\title{
Logistics of smart supply chains
}

\author{
Vladimir Scherbakov \\ Department of Logistics and Supply \\ Chain Managemen \\ St. Petersburg State University of \\ Economics \\ St. Petersburg, Russian Federation \\ shefainn@yandex.ru
}

\author{
Galina Silkina \\ Graduate School of Business and \\ Management \\ Peter the Great St.Petersburg \\ Polytechnic University \\ St. Petersburg, Russian Federation \\ galina.silkina@gmail.com
}

\begin{abstract}
The initial study principle is the axiom of supply chains as the forms of logistics arrangement in the sphere of commodities and services circulation on the "simple-tocomplex" development basis: direct - advanced - maximum chains of supply - networks of supply chains. In the frame of evolutionary dynamics, the basic concept of Supply Chain Management (SCM) with its fundamental idea on integrated management of logistics business-processes based on processing the on-line information related to material flow is interpreted as the concept of adaptive management of logistical flows under the conditions of chain organization and logistics digitization.

The digitalization is understood as a digital logistics transformation, which activates the information processes in supply chain management with arrangement of customeroriented networks of manufacturers, suppliers of goods, logistics service providers, and is considered by an objective prerequisite for the phenomenon of smart supply chains.

The developed scientific understanding of smart supply chains and their intellectual functionality when forming the value propositions in effective ways is associated with the modern economic realities of the Industry 4.0 and the prospects for using analytical tools, digital information technologies as the main operational tools of the network logistics infrastructure. There is the description of the precedents and perspectives of using descriptive, diagnostic, predictive, and prescriptive analytics, Big Data technologies, artificial intelligence, the Internet of things, blockchain in solving functional logistics problems created in the world business practice.

A comparative characteristic of the model for interaction of participants in smart supply chains relative to the traditional model is given. The potential of the smart supply chains logistics (by signs: speed, adaptability, accuracy) in achieving the customer-oriented approach of the integrated business is assessed.
\end{abstract}

Keywords - supply chain network, smart technologies, logistics digitalization, self-regulatory logistics operations

\section{INTRODUCTION}

Terminological dictionaries define the supply chain as a set of organizations, people, processes, information, technologies and resources involved in creating the product value at all stages of production and distribution from sources of raw materials through production to the end user through flows of information, physical distribution and cash [1].

Over the past almost 40 years, the concept of the supply chain proposed in 1982 by K. Oliver [2] has undergone major changes. The current generation supply chains grow from traditional individual desynchronized economic relations, linear models and simple network configurations to connected, scalable, adaptable, harmonized partner networks [3] (Fig. 1).

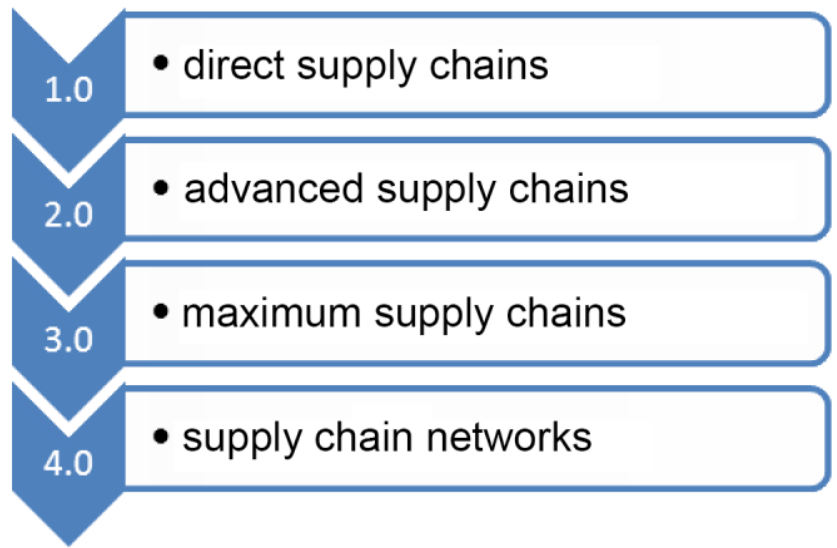

Fig. 1. Supply chain evolution

The direct supply chain (Supply chain 1.0) consists of a focal (central) company, generally, an industrial enterprise or a trading company, supplier and buyer/consumer. In this case, the focal company determines the chain structure and the ways of managing relations with business partners.

The advanced supply chain (Supply chain 2.0) additionally includes second-level suppliers and users and is the basis for creation of the reference model of operations in the supply chains - the SCOR model developed by the Supply Chain Council (SCC) for their analysis, effective planning, design and currently recognized as an international standard.

The maximum supply chain (Supply chain 3.0) consists of a focal company and all its contractors, from suppliers of raw materials and natural resources that determine the resources of the focal company, and the distribution network up to end users, as well as logistics, institutional and other intermediaries [4].

Along with the development of really supply chains, the scale of managerial tasks also changed. What used to be a purely operational logistics function that focused on supplying for the needs of production and delivering products to users has evolved over time into a full-blown supply chain management concept (SCM). Being the most common concept of building relations between contractors, 
the SCM requires scientific-methods support, which explains the flow of works in this direction.

Historically, the main interest of researchers was focused on finding answers to questions: how to make the supply chain management leaner and how to make the supply chain management more flexible [5]. The first approach supposes the reduction of production and operating costs, including through the reduction of inventories and the active use of "just-in-time" supply practices, as well as coordinated planning, reallocation of resources, and sharing of responsibilities and risks. The second approach is focused on an operational response to change of needs, demand, conditions of competition and cooperation. Each of these approaches has proven the effectiveness in the respective industries.

However, despite significant changes in the composition, structure and organization, the traditional supply chains of the first and third generations remained largely a sequence of discrete, disparate measures in marketing, production, distribution, and delivery of products.

In the most companies, customer satisfaction is accomplished through a very standardized process. The marketing analyzes consumer demand and tries to predict it for the coming period. Based on these forecasts, orders for materials and components are formed; facilities and the production properly are planned. Distribution, taking into account forecasts and plans, informs the customer about the estimated time of products delivery. If events develop in accordance with the plans drawn up, users will receive the products they need in the right place and in time, but this does not happen as often as we would like.

The forecasting methods remain quite inaccurate; in addition, the data, which these methods rely on, are often irrelevant, inconsistent and incomplete. Production sometimes works without proper coordination with marketing, the capabilities of suppliers and other partners. The lack of transparency in the chain form the situations where in some chain nodes there is no full understanding of what is happening in others, which leads to uncoordinated actions. Constantly growing customer needs and the changed logic of contractors' interaction have determined the transformation of traditional supply chains into modern networks - Supply chains 4.0 or smart supply chains.

A new stage of the evolution of supply chains and their transformation to model 4.0 is logical and is due to at least two intertwining trends:

- variable customer expectations. More accurate and individual customer expectations encourage companies to develop customer-oriented, reliable and transparent supply chains. And these transformations have already begun. According to the study by the consulting company $\mathrm{PwC}$, based on a survey of more than 2000 respondents, more than $30 \%$ of them say that they have already begun network transformation, and in general more than $70 \%$ plan to do this over the next five years, expecting an increase in efficiency by $4.1 \%$ annually while increasing revenue by $2.9 \%$ per year [6]

- the evolution and revolutionary transformation of technologies.
As a rule, the business practice is ahead of the theory development, and innovative management decisions and tools go beyond the formed paradigms. The happened changes require adequate theoretical understanding, which specifies the relevance of this paper. In a practical aspect, the study of smart supply chains will help determine the necessary formation tools and adequate management techniques.

\section{MATERIALS AND METHODS}

The study purpose is to identify the essential characteristics and unique features of smart supply chains, as well as the current state and trends of their application in business. During the study, the best world practices were analyzed, the materials of the reports of leading consulting companies and reputable analytical agencies were studied.

During the study, general scientific methods - system analysis, comparison, description, generalization, systematization, and special techniques were used.

Theoretical understanding and then the transition to smart supply chains require three key factors: formation of clear definition, selection of appropriate tools and analysis of new opportunities.

\section{RESULTS}

Currently, the term "smart object" is one of the most popular and frequently found in the literature, but its exact understanding has not yet been formed. The devices with built-in computer and software that can automatically execute a part of the tasks conventionally performed by human are often called smart. The device functions are usually limited by the capabilities of this software (smart watches, smart home, etc.).

However, really smart, intelligent objects are something more. Only those that are broader functionality than traditional ones should be recognized as fully intelligent and can perform various actions that are more complex than usual, while acting in an autonomous or semi-autonomous mode. A smart object is one that saves time and resources, provides a comfortable and safe environment and provides transparent and technological interaction [7].

When applying to supply chains and their management, the property of intelligence comes to the following fundamental points.

The formation of supply chains always has the priority purpose of the effective service of demand. The conventional SCM procedures are not able to identify what value of the potential proposal for a particular user is and to realize this proposal in the most efficient way. However, namely these requirements are designed to satisfy the modern smart supply chains 4.0 (fig. 2), the purpose of the formation of which is very ambitious - to build a fundamentally new type of interaction networks. 


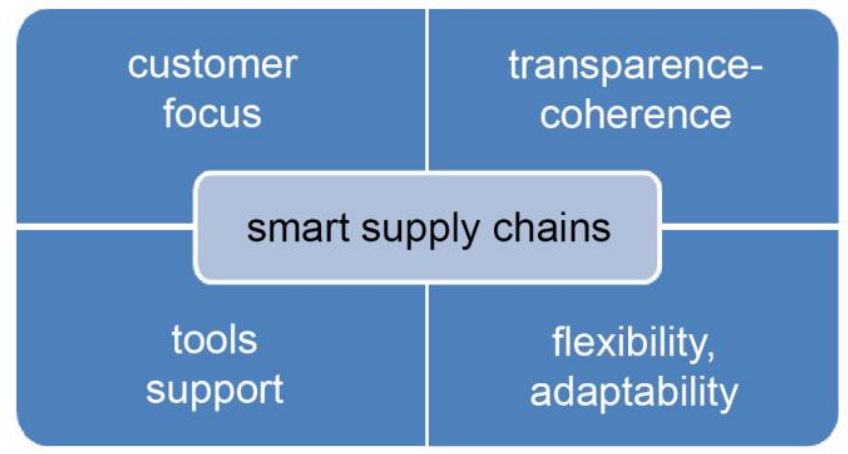

Fig. 2. Properties of smart supply chains

Customer focus is the transformation of the conventional supply chain into the customer value chain. In this case, the respective requirements and signals can occur at any node or even the entire network simultaneously.

Transparency and coherence are that the all participants in the supply chain shall work toward a common goal, and the ongoing processes shall be intelligible to all. Low level of critical raw materials, production shutdown and sudden change in user preferences - all this information will be simultaneously available to all network nodes. This will allow contractors to build the agreed plans and jointly facilitate their implementation.

Flexibility and adaptability are quick response to variability in markets with strict compliance with the standards and the applicable legislation. The transparency will allow companies not only to respond to deviations, but to forecast them through network simulation and scenario building, to edit on a real time basis immediately after conditions change.

Tooling support is providing powerful analytical tools for substantiating and making managerial decisions.

\section{DISCUSSION}

\section{A. Tooling support of smart supply chains}

New additional functionality of modern supply chains is provided by implementing the innovative and also "smart" technologies.

The smart technologies are understood as an umbrella term, the collective name for modern high technologies, which are characterized by a high degree of internal selforganization and synergy, a large number of feedbacks both positive ones which contribute to "acceleration" of the system and its subsequent evolution, and negative ones which controls the system, which do not allow to "runaway" ensuring its normal, rhythmic life support $[8,9]$.

First of all, these are analytical tools, artificial intelligence (AI), Internet of things (IoT), blockchain technology $[10,11,12]$. The convergence of advanced analytics, AI, IoT, and blockchain combined with more conventional supply chain management systems and business network practices, provides new levels of efficiency.

Since all the listed information technologies at the current stage of computer technology development are digital, the transformation of supply chains towards increasing their "intelligence" is justifiably called digitalization, and the smart chains 4.0 are called digital supply chains (DSC).

Specialists of The Hackett Group, Inc. - Strategic consulting company involved in comparative analysis and implementation of practices for global companies have prepared a special review regarding the role of analytics in the supply chain digitalization [13]. It substantiates that the advanced analytics and the respective decision-making shall be in the spotlight, since only they are the basis for digital transformation.

Hackett Group has found that most industry leaders (66\%) have understanding of the need to urgently implement supply chain analytics and that the advanced analytics is critical for their supply chain operations in 2-3 years coming. The informational basis for the use of analytical tools is called as the collection, integration and systematization of significant amounts of data, as well as their processing using the Big Data technologies [14, 15].

The continuum of capabilities of supply chain analysis provides the full range of tools, differentiated based on the requested information and the needs of decisions made:

- descriptive analytics that answers the question "What's happened?". It uses retrospective data to generate reports, but it does not provide much for understanding the ways to improve the business performance;

- diagnostic analytics ("Why has this happen?") forms a deeper layer of analysis based on cause-effect relations identified by means of descriptive analytics. It is used to explain the cause of certain events;

- predictive analytics ("What will happen?") provides a transition from historical reviews and root cause analysis to forecasting events. It provides the possibility of not reactive actions but active ones;

- prescriptive analytics ("What needs to be done to succeed?") is aimed at optimizing the company's operation and transition to specific events [16]

According to the McKinsey consulting company, the approach to supply chain management 4.0 using predictive analytics can reduce delivery times to several hours. Amazon, an American retailer, already has a patent for a predictive shipment model that assumes that the goods begin to be delivered before the order is placed. In other words, as soon as the customer completes the purchase, the product that has already been launched into the supply chain by the "smart" system will be redirected to it [17].

The artificial intelligence (AI) technologies are based on the use of computer algorithms that simulate various aspects of human thinking, and are smart technologies simply by virtue of their definition.

Over the next few years, it is expected that the artificial intelligence will be used in every application, program or service at one level or another. Smart devices that operate semi-autonomously or autonomously in an uncontrolled and censorship-tolerant environment will create a new intellectual layer between people and systems. The smart devices distribution is associated with the expected transition from discrete solutions to their clusters, including 
in supply chains. In this model, several devices will work together, independently or under human control.

Due to computer-aided learning technologies, the smart supply chain will be able to dynamically respond to market changes, adapt and make independent decisions. The artificial intelligence tools help, for example, to predict future unformed needs and to develop a production plan based on the actual demand.

According to SAP, having implemented the smart supply chain, the companies can increase revenue from new products by an average of $10-20 \%$, and reduce their speed of market launch down to $55 \%$. In addition, due to dynamic frequently updated forecasts, logistics costs will decrease by $-12 \%$, and planning costs - by $-15 \%$. Due to the increased transparency of inventories, the level of unbudgeted expenditure will decrease by $20 \%$ [18].

Finally, the highest expression of artificial intelligence technologies application can be the creation of a digital twin of the physical supply chain, which will allow for virtual testing of management decisions to quickly respond to new opportunities or threats, and new market challenges. Unlike the conventional model, the model of participants' interaction in the digital supply chain is based on knowledge of loading of production equipment interfaced with the Internet and optimizes transaction costs, as a result of which the chain becomes self-optimizing to ensure the result being the most effective for the end users.

The analysts recognize the Internet of things as the most significant in terms of the impact on logistics in general and supply chain management. The existing concentrated achievements and challenges reflect the shared report of DHL and Cisco: "If you imagine those millions of objects to be sent, moved, tracked and interacted with various mechanisms, vehicles and people, it is not surprising that the Internet of things and logistics are ideally suited to each other" [19]. The IoT marks a major logistics revolution that is expected for the next decade.

In its glossary the Gartner defines the Internet of things as a physical objects network that incorporates the technology allowing them to communicate, record parameters, and exchange data via internal and external channels. Network-forming objects have autonomous support, are controlled by intelligent systems and autonomously connected to the Internet, can execute their own or cloud applications, analyze, transmit and receive data from other objects.

The Internet of things allows to create dynamic networks consisting of billions of interacting "things" (applications, services, middleware components, terminal devices), which ensures the integration of the digital and physical worlds. As a result, a completely new environment is formed, where the intelligence embodied in applications allows evaluating the events taking place in the physical world, to take into account the gained experience to support decision making. In such an environment, fundamentally new conditions are created for industrial production, business conducting, protection, etc.

The IoT concept suggests: some day, things will become active participants in business, information and social interactions, where they can communicate with each other, while exchanging information about their condition and the environment, responding and influencing the processes in the outworld without human intervention. The possibilities of the Internet of things will increase all the time, which will lead to formation of the Internet of Everything (IoE). The Internet of Everything allows smart objects to be active participants in self-regulating logistics operations that are controlled by events.

3D printing and robotics shall also facilitate the immersion of supply chains in digital reality. The combination of analytical tools and the data flow from devices in the Internet of Things will allow us to create new models and data structures, and 3D printing and robotics will become those drivers that will "force" the supply chain to develop more actively.

The blockchain technology can guarantee transparency of the entire supply chain. It allows tracking information about the product origin, placing orders, and also performing transactions in the digital trust environment. Now, such solutions are tested at the SAP [20].

The blockchain as a means of information exchange guaranteeing its reliability and inalterability can provide the main effect not when optimizing an individual business, but in the interaction of partners who can better integrate their processes and accelerate them, get rid of complex checks thanks to transparency and reliable data exchange.

From the point of view of the SCM, the blockchain allows to:

- strengthen the integration framework for the interaction of participants in supply chains;

- eliminate unnecessary intermediaries and thereby reduce costs;

- prevent the trafficking in goods and other fraud attempts;

- reduce the workflow time by an order of magnitude

These and other advantages are proved by practice-made precedents [21].

Since 2016, startup Yojee (Singapore) has been operating - the technology platform that provides powerful logistics capabilities in supply chain management using the artificial intelligence and blockchain technologies. It replaces a dispatcher, monitors the order status in real time, generates accounts and manages tasks. The company declares that it already works with 30,000 vehicles and customers from Singapore, Australia, Cambodia and Indonesia.

In 2017, Australia conducted a comprehensive testing of the TBSx3 security system based on the blockchain architecture, the purpose of which is to reach a qualitatively new level of protection of global supply chains in the intermodal wine supply chain from the Kunavarra region (South Australia) to the Qingdao Chinese port (length route - $8100 \mathrm{~km}$ ) using road and sea transport. The development is based on a 44-bit alphanumeric encoding adopted in the military-industrial complex.

The Intel has demonstrated the blockchain platform operation for tracking seafood supply chains. The platform allows effectively controlling the production of seafood, 
increases the accuracy and reliability of their accounting, starting from the catch time, and facilitates to comply with the storage conditions of goods in accordance with the sanitary requirements.

\section{B. Smart supply chain potential}

The increased interest in the digital transformation of supply chains is motivated by the related consequences. The name itself is smart, and the number of the current stage in development of supply chains is 4.0 , which suggests their connection with Industry 4.0, which implies fully automated production controlled by intelligent systems in real time. For business, this means a transition from the automation of individual processes to complex transformation. Intelligent supply chains are becoming an integral part of smart digital production.

The results of a comparative analysis of Supply Chains 4.0 and conventional chains of previous generations for various reasons are given in Table I.

\section{TABLE I. COMPARATIVE ANALYSIS OF CONVENTIONAL AND} SMART SUPPLY CHAINS

\begin{tabular}{|c|c|}
\hline Conventional supply chains & Smart supply chains \\
\hline \multicolumn{2}{|c|}{ Transparency } \\
\hline $\begin{array}{l}\text { Limited overview of the supply } \\
\text { chain }\end{array}$ & $\begin{array}{l}\text { Full overview of the supply } \\
\text { chain }\end{array}$ \\
\hline \multicolumn{2}{|c|}{ Communications } \\
\hline $\begin{array}{l}\text { Information is delayed and } \\
\text { possibly distorted when passing } \\
\text { through the chain }\end{array}$ & $\begin{array}{l}\text { Full and up-to-date information } \\
\text { is simultaneously available for all } \\
\text { chain nodes. }\end{array}$ \\
\hline \multicolumn{2}{|c|}{ Interaction } \\
\hline $\begin{array}{l}\text { Limited chain transparency } \\
\text { prevents meaningful and full } \\
\text { cooperation }\end{array}$ & $\begin{array}{r}\text { Natural development of full } \\
\text { cooperation }\end{array}$ \\
\hline \multicolumn{2}{|c|}{ Flexibility } \\
\hline $\begin{array}{l}\text { End user demand may change } \\
\text { as material flows }\end{array}$ & $\begin{array}{l}\text { Changes of customer needs } \\
\text { are quickly evaluated }\end{array}$ \\
\hline \multicolumn{2}{|c|}{ Feedback } \\
\hline $\begin{array}{l}\text { Various scheduling cycles } \\
\text { leading to delays, and } \\
\text { unsynchronized responses at } \\
\text { various levels }\end{array}$ & $\begin{array}{l}\text { Real-time response at all levels } \\
\text { of planning and execution }\end{array}$ \\
\hline
\end{tabular}

Digitization of the supply chain allows companies to take into account new customer requirements, supply-side problems and other expectations of efficiency increase. Compared to conventional, smart supply chains provide:

- speed. New approaches to the distribution of products - perfect forecasting in combination with modern delivery systems (stand-alone and semi-autonomous devices) can reduce delivery time down to several hours;

- adaptability. Continuous planning Supply Chain 4.0 enables companies to dynamically respond to changing requirements or constraints (for example, real-time IoT production facilities feedback). Even after the products are sent, the flexible delivery processes allow the customers to redirect cargoes to the most convenient destination. Supply chain flexibility is also provided by new business models. Instead of relying solely on internal resources, the companies can acquire individual supply chain functions as a service. Increased specialization of service providers creates economies of scale and scale while increasing the potential for outsourcing.
- accuracy. Smart technologies provide real-time endto-end transparency over the supply chain. The information range extends from synthesized upper level key performance indicators such as the overall level of service to very detailed process data such as the exact location of the trucks in the network. Integration of this data into the "supply chain cloud", - a joint platform for communication between customers, production companies, suppliers, etc. providing a common logistics infrastructure and/or joint solutions, ensures that all concerned parties in the supply chain are guided and make decisions based on the same facts.

In total these processes provide significantly higher efficiency of smart digital supply chains than conventional ones.

\section{CONCLUSIONS}

The transition to the formation of new generation Supply Chains 4.0 - smart supply chains - is inevitable and is due to two complementary trends - changing users requirements and the development of information tools of their support like Stand. Abbrev., in press. This process is extremely complex. And no company has fully completed this transition yet. However, those who do this first will gain significant competitive advantages.

\section{REFERENCES}

[1] Klaus P., Krieger W. (Hrsg.). “Gabler Lexikon Logistik”. Dr. Th. Gabler Verlag, 2008.

[2] Oliver K., Webber M. "Supply Chain Management: Logistics Catches Up with Strategy" in Logistics, The strategic issues. Champan and Hall: London, 1982, pp. 63-75.

[3] "The 2017 MHI Annual Industry Report Next-Generation Supply Chains: Digital, On-Demand and Always-On The 2017 MHI Annual Industry Report Next-Generation Supply Chains: Digital, On-Demand and Always-On": [Electronic resource]. URL: https://www2.deloitte.com/content/dam/Deloitte/pl/Documents/Repor ts/pl_MHI_Industry_Report_2017.pdf. (accessed date is 16.04.2018).

[4] Lysons K., Gillingham M. "Purchasing and Supply Chain Management". $6^{\text {th }}$ Edition. Prentice Hall, 2005.

[5] K.V. Krotov. "Trends for development of the supply chain management concept". St. Petersburg: Law Enforcement Academy SPbGU, 2010

[6] "Industry 4.0: How digitization makes the supply chain more efficient, agile, and customer-focused: [Electronic resource]. URL: https://www.strategyand.pwc.com/rep"ort/digitization-more-efficient (accessed date is 18.06.2019).

[7] "Smart and Human" in Expert. 2018. 2769, pp. 16-17.

[8] Sun, P.K., Vorona-Slivinskaya, L., Voskresenskay, E. Improvement of economic security management system of municipalities with account of transportation system development: Methods of assessment (2017) 90 (1), статья № 012073.

[9] Levina, A.I., Dubgorn, A.S., Iliashenko, O.Y. Internet of things within the service architecture of intelligent transport systems (2018) pp. 351-355.

[10] Kelly R. "The Inevitable: Understanding the 12 Technological Forces That Will Shape Our Future". N.Y.: Penguin Group, 2016.

[11] Schwab K., Davis N. "Shaping the Fourth Industrial Revolution". World Economic Forum, 2018.

[12] Mougayar W. "The Business Blockchain: Promise, Practice of the Next Internet Technology". Wiley, 2016.

[13] "Analytics: Laying the Foundation for Supply Chain Digital Transformation". The Hackett Group, 2017.

[14] Mayer-Schönberger V. "Big data. The revolution that will change the way we live, work and think". M: Mnn, Ivanov and Ferber, 2014 
[15] Cielen D., Meysman A., Aly M. "Introducing Data Science. Shelter Island: Manning", 2016.

[16] Franks B. "The revolution in analytics: How to improve your business with operational analytics in the Big Data era "/ M $\therefore$ Alpina Publisher, 2016.

[17] "Supply Chain 4.0 - the next-generation digital supply chain" [Electronic resource].

URL: https://www.mckinsey.com/ /media/McKinsey/Business\%20Functio ns/Operations/Our\%20Insights/Supply\%20Chain\%2040\%20\%20the $\% 20$ next\%20generation\%20digital\%20supply\%20chain/08b1ba29ff4 595ebea03e9987344dcbc.ashx (Accessed date is 14.06.2019).

[18] Ilin, I., Kalinina, O., Barykin, S. Financial logistics innovations in IT Project Management (2018) 193, 05062.
[19] "Digital technologies for the advanced supply chain. How to survive and achieve success in the era of the digital economy": [Electronic resource]. URL: https://www.sap.com/cis/products/digital-supplychain.html (Accessed date is 25.10.2017)

[20] "Internet of Things in the logistics: Shared Report of DHL and Cisco 2015": [Electronic resource]. URL: http://json.tv/tech_trend_find/internet-veschey-v-logistikesovmestnyy-otchet-dhl-i-cisco-20160511113055 . (accessed date is 22.09.2017).

[21] Silkina G.Yu., Scherbakov V.V. "Current Trends in Logistics Digitalization.” St. Petersburg: POLITEKH-PRESS, 2019. 